\title{
Impact of tumor dimensions and lymph node density on the survival of patients with hypopharyngeal squamous cell carcinoma
}

This article was published in the following Dove Press journal: Cancer Management and Research

\author{
Lu-Lu Ye $e^{1,2, *}$ \\ Jia $\operatorname{Rao}^{2,3, *}$ \\ Xing-Wen Fan ${ }^{1,2}$ \\ Qing-Hai Ji ${ }^{2,4}$ \\ Chao-Su Hu, ${ }^{1,2}$ \\ Hong-Mei Ying ${ }^{1,2}$ \\ 'Department of Radiation Oncology, \\ Fudan University Shanghai Cancer \\ Center, Shanghai 200032, P.R. \\ China; ${ }^{2}$ Department of Oncology, \\ Shanghai Medical College, Fudan \\ University, Shanghai 200032, P.R. \\ China; ${ }^{3}$ Department of Pathology, \\ ${ }^{4}$ Department of Head and Neck \\ Surgery, Fudan University Shanghai \\ Cancer Center, Shanghai 200032, P.R. \\ China \\ *These authors contributed equally to \\ this work
}

Correspondence: Hong-Mei Ying Department of Radiation Oncology, Fudan University Shanghai Cancer

Center, 270 Dongan Road, Shanghai 200032, P.R. China

Tel $+8621 \quad 64175590$

Fax +86216417477

Email dryinghongmei@।63.com
Purpose: To analyze the potential variables affecting the survival of patients undergoing primary surgery for hypopharyngeal squamous cell carcinoma.

Patients and methods: Between August 2007 and December 2016, 93 patients with primary hypopharyngeal squamous cell carcinomas undergoing radical surgery at Fudan University Shanghai Cancer Center were reviewed. The clinicopathological features were analyzed retrospectively. The optimal cutoff values were determined based on the receiver operating characteristic curve analysis. Pearson correlation coefficients were used to assess the correlations between variables. The Kaplan-Meier and Cox proportional hazard methods were used to evaluate the impact of variables on overall survival (OS), disease-specific survival (DSS), and disease-free survival (DFS).

Results: Cox multivariate analysis revealed that a depth of invasion (DOI) $\geq 4.3 \mathrm{~mm}$ was correlated with inferior OS $(P=0.045)$, DSS $(P=0.046)$, and DFS $(P=0.046)$. A primary tumor volume (PTV) $\geq 0.36 \mathrm{~mL}$ was related to poor $\mathrm{OS}(P=0.018)$, DSS $(P=0.026)$, and DFS $(P=0.036)$. A lymph node density $(\mathrm{LND}) \geq 0.07$ was also associated with worse OS $(P=0.014)$ and DSS $(P=0.045)$. Moreover, additional prognostic value was observed in the combined use of PTV and LND.

Conclusion: The DOI, PTV, and LND obtained from the surgical specimens could provide additional valuable information for prognostic stratification and allowed the more appropriate selection of suitable candidates for more aggressive adjuvant therapy.

Keywords: hypopharynx, surgery, depth of invasion, primary tumor volume, lymph node density, survival

\section{Introduction}

Hypopharyngeal cancer is not very prevalent accounting for $2.8 \%-6.5 \%$ of upper aerodigestive tract (UADT) cancers. ${ }^{1-3}$ Tumors arising from the hypopharyngeal regions have specific clinicopathological characteristics distinguishing them from other UADT cancers. ${ }^{4-7}$ At diagnosis, $56.7 \%-80.5 \%$ of patients have T3/T4 disease and $56.7 \%-83.7 \%$ have regional nodal metastasis $(\mathrm{N}+)$. Approximately $70 \%-87 \%$ of tumors are in advanced stages (III/IV disease) at initial presentation., ${ }^{4,5-12}$ Despite aggressive combined treatment modalities, the prognosis of hypopharyngeal cancer remains the worst among UADT cancers. ${ }^{1-3}$

Traditionally, surgical ablation remains the preferred approach for treating hypopharyngeal cancer. Postoperative radiotherapy/chemoradiotherapy is recommended for adverse pathological features in accordance with the National Comprehensive Cancer Network (NCCN) Clinical Practice Guidelines. ${ }^{13}$ Nevertheless, the outcomes remain compromised, with 5-year overall survival (OS) rates ranging from $41 \%$ to $55 \%$. ${ }^{8,9,11,12,14}$ 
Understanding the significance of the primary tumor characteristics and regional nodal metastases is of critical importance for gaining important insights into cancer growth and enabling more rational therapy decisions in clinical practice. We have previously demonstrated that some pathological characteristics are important prognostic factors. ${ }^{8}$ The lymph node density (LND) in hypopharyngeal cancer is believed to be of greater prognostic value than traditional nodal staging, ${ }^{8,11,12,14}$ which is calculated as the number of metastatic lymph nodes (LNs) divided by the total number of resected LNs. Additionally, the depth of invasion (DOI) ${ }^{15-17}$ and the primary tumor volume $(\mathrm{PTV})^{9,10,18}$ are found to provide prognostic information in hypopharyngeal cancer. The DOI is measured as the deepest structure reached by the primary tumor. The PTV is a threedimensional concept that can be calculated with a modified formula ${ }^{19,20}:$ PTV $(\mathrm{mL})=$ tumor maximal diameter $(\mathrm{mm})$ $\times$ tumor minimal diameter $(\mathrm{mm}) \times$ DOI $(\mathrm{mm}) \div 2 \times 10^{-3}$. In this study, we sought to gain a further insight into potential variables of surgical specimens that might hold promise for improving prognosis.

\section{Patients and methods}

\section{Study population}

This retrospective study was approved by the Institutional Review Board of the Fudan University Shanghai Cancer Center. All patients provided written informed consent to participate. The study was performed in accordance with the principles of the Declaration of Helsinki and its amendments.

Between August 2007 and December 2016, the medical records of patients with primary hypopharyngeal squamous cell carcinoma (HPSCC) undergoing radical surgery at the Fudan University Shanghai Cancer Center were reviewed. The eligibility criteria were as follows: 1) histologically confirmed SCC in the hypopharyngeal region; 2) received radical resection of primary tumor and metastatic LNs with negative margin microscopically; 3) cervical nodal status initially evaluated with contrast-enhanced MRI or computed tomography (CT) preoperatively; 4) no preoperative chemotherapy or radiotherapy; and 5) no previous history of cervical LN dissection. Patients who were diagnosed with carcinoma in situ, who underwent incomplete primary tumor dissection with positive margin, or who experienced HPSCC recurrence were excluded.

Patients were screened with a full workup before treatment, including a complete medical history, physical examination, electronic laryngoscope examination, esophageal barium meal examination, contrast-enhanced MRI or CT scan of the neck, plain chest CT scan, abdominal ultrasound, whole-body single-photon emission CT bone scan, complete blood count, and serum biochemistry profile. The tumor stage was classified using the seventh edition of the American Joint Committee on Cancer (AJCC) staging system.

\section{Surgery and adjuvant therapy}

All patients underwent radical hypopharyngectomy and neck nodal dissection. Radical neck dissection was performed ipsilaterally in patients with clinically positive nodal metastasis (cN+), which involves levels II to VI or level I involvement. In case of contralateral clinically negative nodal metastasis ( $\mathrm{cN}-$ ), elective neck dissection (END) for contralateral neck was carried out in patients with tumors approaching or crossing the midline of the sagittal plane or tumor arising from the posterior wall or postcricoid regions. With regard to bilateral $\mathrm{cN}-$, ipsilateral END was adopted in patients with lesion in pyriform sinus unilaterally not approaching the midline. Otherwise, bilateral END was performed. The scope of END included levels II to IV or level VI involvement.

Postoperative radiotherapy was recommended based on pathological findings, including 1) a primary pathological tumor classification (pT) of 3 or above, 2) close margins $(<5 \mathrm{~mm}), 3)$ a pathological nodal classification $(\mathrm{pN})$ of 2 or above, 4) extracapsular spread (ECS) of the LN, 5) perineural invasion, and 6) lymphovascular invasion. Radiotherapy was administered in the form of intensity-modulated radiotherapy with 6 megavoltage photons. The prescribed dose was 2.0 Gy in a daily fraction, given 5 days per week. The total dose was 60 Gy to high-risk microinvasive areas (CTV1) and 54 Gy to low-risk areas (CTV2). The CTV1 included the tumor bed of primary lesion with a concentrically isotropic margin of $2 \mathrm{~cm}$ in upward and downward directions, lymphatic areas of level II, III, VA, and VIII, and the station of the pathologically positive lymph nodes. The CTV2 were the lymphatics of level IV and VB. The tumor bed was boost to $66 \mathrm{~Gy}$ in selective cases with extensive preoperative tumor load. CTV2 was not considered in case of $\mathrm{pN} 0$ classification. For patients with ECS, concurrent chemotherapy with cisplatin-based agents was administered at $80 \mathrm{mg} / \mathrm{m}^{2}$ every 3 weeks or 40 $\mathrm{mg} / \mathrm{m}^{2}$ weekly.

\section{Follow-up and clinical endpoints}

After the completion of treatment, patients received regular examinations at outpatient clinics at 3-month intervals during the first 2 years, every 6 months in the third to fifth years, and annually thereafter. 
The endpoints were OS, disease-specific survival (DSS), and disease-free survival (DFS). All endpoints were defined as the time interval between the initial therapy and the date of failure. For patients who were still alive or showed no progressive disease, the latest date of follow-up was recorded.

\section{Histopathological analysis}

All surgical specimens were oriented and labeled by the surgeons before being fixed in $10 \%$ buffered formalin and embedded in paraffin. The specimens were sectioned for routine H\&E staining. The histopathological review was performed by two experienced pathologists who were blinded to the patients' medical information. When significant disagreement occurred, a third pathologist was needed to minimize the deviation. The DOI was measured from the basement membrane to the deepest point of the tumor. The dimension A was taken in exophytic tumor (Figure 1A) and dimension $\mathrm{B}$ in ulcerative type (Figure 1B).

\section{Statistical analysis}

The SPSS version 22.0 (IBM, Armonk, NY, USA) was used for the data analysis. Receiver operating characteristic (ROC) analysis was applied to evaluate the optimal threshold values of variables for predicting survival. Pearson correlation coefficients were used to assess the correlations between variables. Survival curves for OS, DSS, and DFS were obtained utilizing the Kaplan-Meier method. Log-rank tests were performed to explore the significance of the tested variables on survival outcomes. Univariate and multivariate Cox proportional hazards regression analyses were carried out to assess the significance of variables associated with clinical outcomes. All variables identified in the univariate analysis were entered into the multivariate analysis. Logminus-log plots were used to evaluate the proportional hazard

A

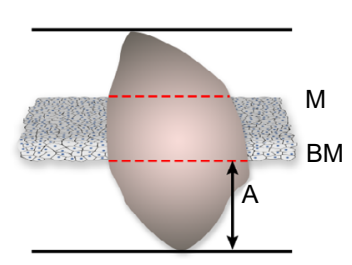

Figure I Measurement methods for depth of invasion from basement membrane to the deepest point of tumor: dimension $A$ in exophytic specimen $(\mathbf{A})$ or dimension $B$ in ulcerative specimen (B).

Abbreviations: BM, basement membrane; $M$, mucosal surface. assumption. Any result with a two-sided $P$-value $<0.05$ was considered statistically significant.

\section{Results Basic characteristics}

A total of 93 HPSCC patients were eligible for this study, and their clinicopathological features are provided in Table 1. The affected subsites were the pyriform sinus in 81 cases, the postcricoid area in 6 cases, and the posterior pharyngeal wall in 6 cases. All patients underwent neck nodal dissection, $31(33.3 \%)$ received bilateral dissection, and $62(66.7 \%)$ had unilateral dissection. Based on the seventh edition of the AJCC staging system, there were $6(6.5 \%)$ patients in stage I, 6 (6.5\%) in stage II, 14 (15.1\%) in stage III, and 67 $(72.0 \%)$ in stage IV.

In general, the median follow-up time was 33.1 months, ranging from 6.1 to 110.7 months. Throughout the period, 23 (24.7\%) patients developed locoregional recurrence, 32 (34.4\%) experienced distant metastasis, and 38 (40.9\%) died. The 3- and 5-year OS, DSS, and DFS rates were $72.9 \%$, $64.9 \%, 63.4 \%$, and $52.0 \%, 50.3 \%, 45.8 \%$, respectively.

ROC curve analysis was performed to evaluate the optimal cutoff values of the potential variables for mortality. Cutoff thresholds of 4.3, 0.36, and 0.07 were chosen for the DOI, PTV, and LND, respectively.

\section{Survival analysis}

In terms of the DOI, there were 68 (73.1\%) patients with DOI $\geq 4.3 \mathrm{~mm}$ and 25 (26.9\%) with DOI $<4.3 \mathrm{~mm}$. Patients with higher DOI had inferior OS (3-year: $68.7 \%$ vs $85.4 \%$; 5-year: $44.7 \%$ vs $75.9 \%, P=0.006$; Figure $2 A$ ), DSS (3-year: $59.6 \%$ vs $80.0 \%$; 5 -year: $40.9 \%$ vs $80.0 \%, P=0.002$; Figure 2B), and DFS (3-year: $59.6 \%$ vs $73.3 \%$; 5-year: $39.1 \%$ vs $65.2 \%, P=0.004$; Figure $2 \mathrm{C}$ ). With regard to the PTV, there were 68 (73.1\%) patients with PTV $\geq 0.36 \mathrm{~mL}$ and 25 (26.9\%) with PTV $<0.36 \mathrm{~mL}$. Similarly, patients with high PTV suffered poorer OS (3-year: $70.6 \%$ vs $79.0 \%$; 5-year: $47.8 \%$ vs $63.2 \%, P=0.031$; Figure 2D), DSS (3-year: $70.6 \%$ vs $76.0 \%$; 5-year: $47.8 \%$ vs $69.7 \%, P=0.013$; Figure $2 \mathrm{E}$ ), and DFS (3-year: $60.9 \%$ vs $70.2 \%$; 5 -year: $41.5 \%$ vs $57.2 \%, P=0.02$; Figure $2 \mathrm{~F})$. Regarding the LND, there were $50(53.8 \%)$ patients with $\mathrm{LND} \geq 0.07$ and 43 (46.2\%) with $\mathrm{LND}<0.07$. Patients with high LND also had worse OS (3-year: $65.2 \%$ vs $82.2 \%$; 5 -year: $46.5 \%$ vs $58.3 \%, P=0.027$; Figure $2 \mathrm{G}$ ) and DSS (3-year: $61.6 \%$ vs $68.4 \%$; 5 -year: $41.6 \%$ vs $63.5 \%$, $P=0.021$; Figure $2 \mathrm{H})$; however, the difference in DFS was insignificant (3-year: $61.6 \%$ vs $65.0 \%$; 5 -year: $41.6 \%$ vs $51.2 \%, P=0.062$; Figure 2I). 
Table I Clinicopathological characteristics of 93 patients with hypopharyngeal squamous cell carcinoma

\begin{tabular}{|c|c|}
\hline Characteristics & $\mathbf{N}(\%)$ \\
\hline \multicolumn{2}{|l|}{ Age } \\
\hline $\begin{array}{l}\text { Mean } \pm \text { SD (range, } \\
\text { years) }\end{array}$ & $56.9 \pm 9.8(32-87)$ \\
\hline \multicolumn{2}{|l|}{ Sex } \\
\hline Male & 91 (97.8) \\
\hline Female & $2(2.2)$ \\
\hline \multicolumn{2}{|l|}{ Cigarette smoking } \\
\hline No & $15(16.1)$ \\
\hline Yes & 78 (83.9) \\
\hline \multicolumn{2}{|l|}{ Alcohol drinking } \\
\hline No & $27(29.0)$ \\
\hline Yes & $66(71.0)$ \\
\hline \multicolumn{2}{|l|}{ Pharyngolaryngectomy } \\
\hline Total & $43(46.2)$ \\
\hline Partial & $50(53.8)$ \\
\hline \multicolumn{2}{|l|}{ Neck nodal dissection } \\
\hline Bilateral & $31(33.3)$ \\
\hline Unilateral & $62(66.7)$ \\
\hline \multicolumn{2}{|l|}{ Tumor differentiation } \\
\hline Well & $4(4.3)$ \\
\hline Moderate & $63(67.7)$ \\
\hline Poor & $26(28.0)$ \\
\hline \multicolumn{2}{|l|}{ Primary tumor subsite } \\
\hline Pyriform sinus & $81(87.1)$ \\
\hline Posterior wall & $6(6.5)$ \\
\hline Postcricoid region & $6(6.5)$ \\
\hline \multicolumn{2}{|l|}{ PT classification ${ }^{\mathrm{a}}$} \\
\hline $\mathrm{TI}$ & $19(20.4)$ \\
\hline $\mathrm{T} 2$ & $40(43.0)$ \\
\hline $\mathrm{T} 3$ & $18(19.4)$ \\
\hline $\mathrm{T} 4$ & $16(17.2)$ \\
\hline \multicolumn{2}{|l|}{$\mathrm{pN}$ classification ${ }^{\mathrm{a}}$} \\
\hline No & $15(16.1)$ \\
\hline NI & $19(20.4)$ \\
\hline $\mathrm{N} 2 \mathrm{a} / \mathrm{b} / \mathrm{c}$ & $\begin{array}{l}\text { I (I.I) / } 49(52.7) \text { / } \\
9(9.7)\end{array}$ \\
\hline N3 & $0(0)$ \\
\hline \multicolumn{2}{|l|}{ pTNM classification ${ }^{\mathrm{a}}$} \\
\hline I & $6(6.5)$ \\
\hline II & $6(6.5)$ \\
\hline III & $14(15.1)$ \\
\hline IV & $67(72.0)$ \\
\hline \multicolumn{2}{|l|}{ DOI } \\
\hline $\begin{array}{l}\text { Mean } \pm \text { SD (range, } \\
\mathrm{mm})\end{array}$ & $6.3 \pm 3.4(0.6-15.0)$ \\
\hline$<4.3 \mathrm{~mm}$ & $25(26.9)$ \\
\hline$\geq 4.3 \mathrm{~mm}$ & $68(73.1)$ \\
\hline \multicolumn{2}{|l|}{ PTV } \\
\hline Mean \pm SD (range, & $2.08 \pm 3.02$ \\
\hline $\mathrm{mL})$ & $(0.02-16.66)$ \\
\hline$<0.36 \mathrm{~mL}$ & $25(26.9)$ \\
\hline$\geq 0.36 \mathrm{~mL}$ & $68(73.1)$ \\
\hline \multicolumn{2}{|l|}{ Tumor differentiation } \\
\hline Well & $4(4.3)$ \\
\hline Moderate & $63(67.7)$ \\
\hline
\end{tabular}

(Continued)
Table I (Continued)

\begin{tabular}{|l|l|}
\hline Characteristics & N (\%) \\
\hline Poor & $26(28.0)$ \\
No. of metastatic LN & $3 \pm 3(0-34)$ \\
Mean \pm SD (range) & \\
Mean \pm SD (range) & $0.11 \pm 0.15$ \\
& $(0.00-0.63)$ \\
$<0.07$ & $43(46.2)$ \\
$\geq 0.07$ & $50(53.8)$ \\
ECS of LN & \\
Negative & $80(86.0)$ \\
Positive & $13(14.0)$ \\
Surgical margin & \\
$\geq 5$ mm & $86(92.5)$ \\
$<5$ mm & $7(7.5)$ \\
Perineural invasion & \\
Negative & $79(84.9)$ \\
Positive & $14(15.1)$ \\
Lymphovascular & \\
invasion & $69(74.2)$ \\
Negative & $24(25.8)$ \\
Positive & \\
Postoperative & \\
treatment & $7(7.5)$ \\
No & $56(60.2)$ \\
RT alone & $30(32.3)$ \\
CCRT &
\end{tabular}

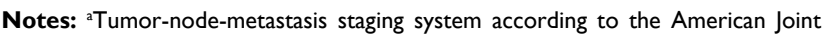
Committee on Cancer (seventh edition).

Abbreviations: CCRT, combined chemoradiotherapy; DOI, depth of invasion; $E C S$, extracapsular spread; LN, lymph node; LND, lymph node density; $\mathrm{pN}$, pathological node; PT, pathological tumor; PTNM, pathological tumor-nodemetastasis; PTV, primary tumor volume; RT, radiotherapy.

Cox univariate analysis (Table 2) indicated that DOI $\geq 4.3 \mathrm{~mm}$ was associated with worse OS $(P=0.010)$, DSS $(P=0.005)$, and DFS $(P=0.007)$. PTV $\geq 0.36 \mathrm{~mL}$ was correlated with poorer OS $(P=0.037)$, DSS $(P=0.017)$, and DFS $(P=0.024)$. LND $\geq 0.07$ was related to inferior OS $(P=0.031)$ and DSS ( $P=0.023)$; however, the relation was not significant in terms of DFS $(P=0.065)$.

Correlations assessed by Pearson correlation coefficients revealed positive correlations among these three variables (Figure S1): DOI and PTV ( $r=0.876, P<0.0001)$, DOI and LND $(r=0.660, P<0.0001)$, and PTV and LND $(r=0.513, P=0.011)$. Because the collinearity would lead to highly unstable estimated regression coefficients, the DOI, PTV, and LND were entered separately into different multivariate regression models.

Cox multivariate analysis (Table 3 ) revealed that the DOI was significantly correlated with OS (HR: 4.513, 95\% CI: $1.034-19.702, P=0.045$ ), DSS (HR: $3.466,95 \%$ CI: $1.022-11.750, P=0.046$ ), and DFS (HR: $3.004,95 \%$ 

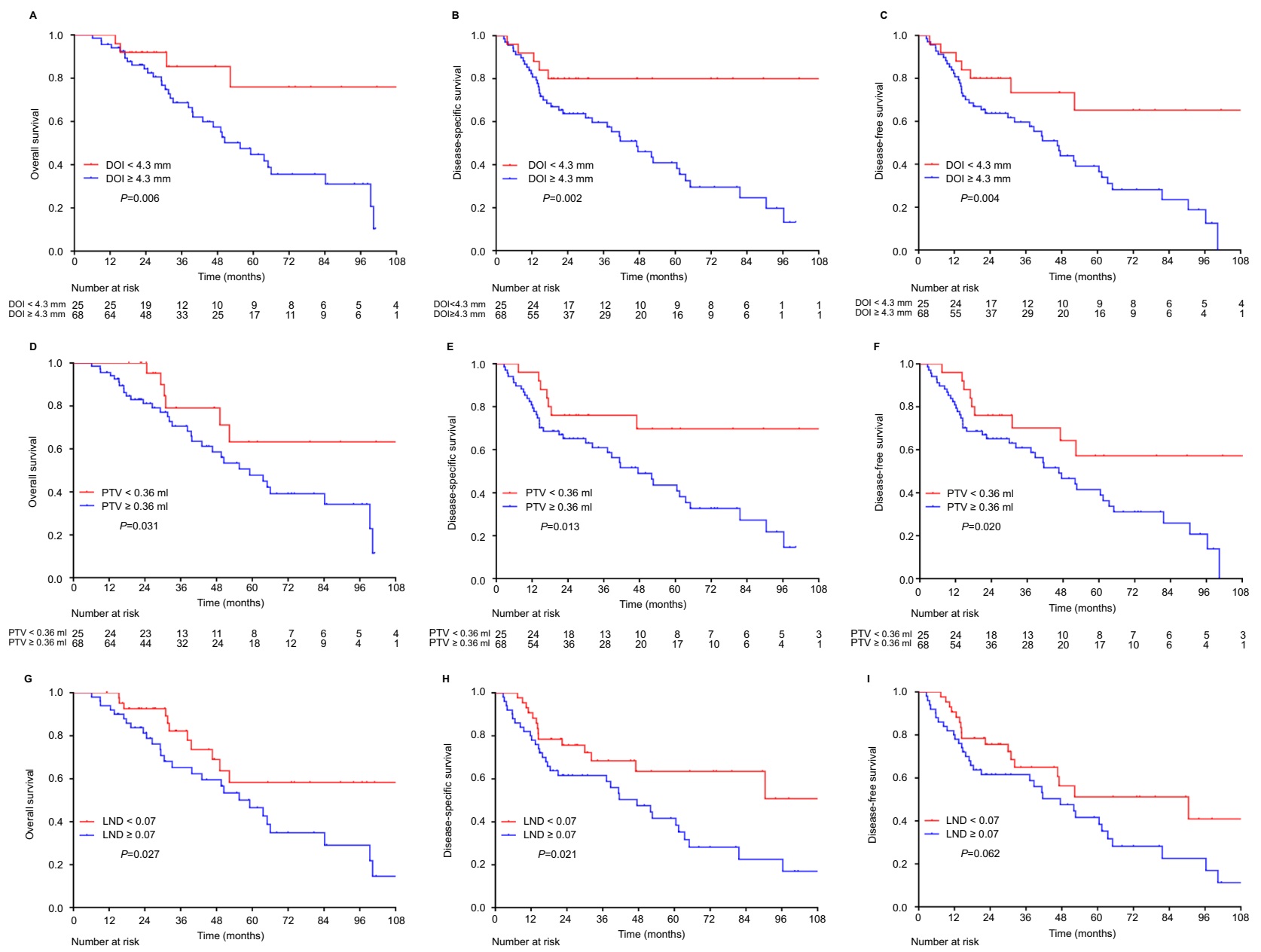

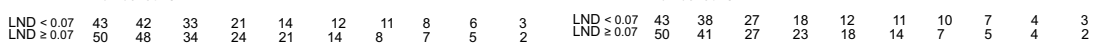
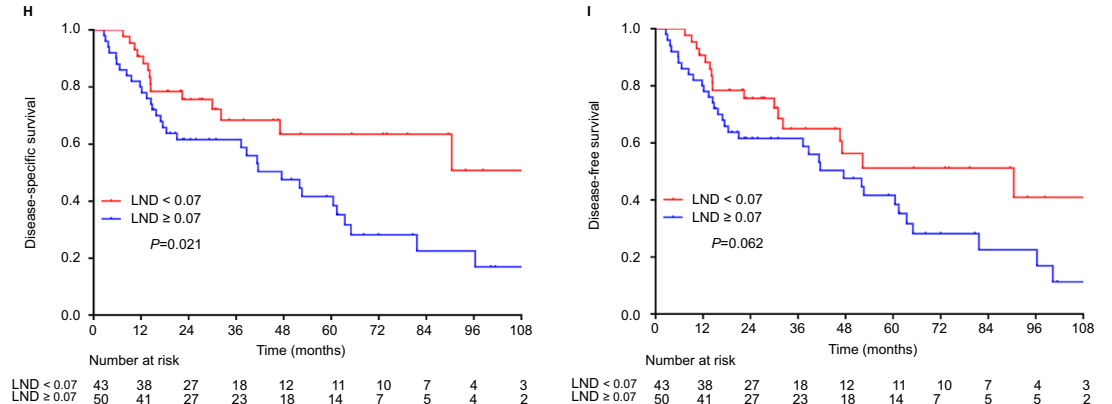

Figure 2 Kaplan-Meier survival curves of overall survival (A, D, G), disease-specific survival (B, E, H), and disease-free survival (C, F, I) according to the depth of invasion (DOI), primary tumor volume (PTV), and lymph node density (LND). Log-rank test, $P<0.05$.

CI: $1.019-8.856, P=0.046)$. The PTV was identified as an independent prognostic predictor for OS (HR: $3.625,95 \%$ CI: $1.242-10.583, P=0.018$ ), DSS (HR: $2.757,95 \% \mathrm{CI}$ : 1.129-6.732, $P=0.026$ ), and DFS (HR: $2.408,95 \% \mathrm{CI}$ : $1.057-5.487, P=0.036)$. On the contrary, high LND was confirmed as an independent prognostic factor for poor OS (HR: $2.854,95 \%$ CI: $1.242-6.560, P=0.014$ ) and DSS (HR: 2.033, 95\% CI: $1.015-4.072, P=0.045)$.

\section{Prognostic scoring system}

A prognostic scoring system was formulated by summing the significant risk factors, as follows: 0 for PTV $<0.36 \mathrm{~mL}$ or $\mathrm{LND}<0.07$; one for PTV $\geq 0.36 \mathrm{~mL}$ or $\mathrm{LND} \geq 0.07$. There were $16(17.2 \%)$ patients with a score of $0,36(38.7 \%)$ with a score of 1 , and $41(44.1 \%)$ with a score of 2.

The data indicated that a score of 0 showed the best OS (5-year: $60.0 \%, 56.6 \%$, and $43.5 \%$, respectively, $P=0.017$;
Figure 3A), DSS (5-year: 76.6\%, 56.5\%, and 37.9\%, respectively, $P=0.008$; Figure 3B), and DFS (5-year: $54.4 \%, 51.4 \%$, and $37.9 \%$, respectively, $P=0.025$; Figure $3 \mathrm{C}$ ) compared with scores 1 and 2 .

\section{Discussion}

Hypopharyngeal cancer is distinguished from other UADT cancers in anatomical structures and biological behaviors. Concealed anatomy and extensive submucosal spread bring about an initial underestimation of the tumor extent and the presence of multifocal lesions. ${ }^{7}$ Cervical metastases are exceptionally frequent due to highly anastomotic lymphatics and signify advanced disease and deteriorated survival. ${ }^{4-7}$

Therapeutic decisions for managing hypopharyngeal cancer remain a crucial matter of debate, especially regarding therapy intensity and sequencing. ${ }^{21}$ Postoperative radiotherapy is administered in the case of $\mathrm{pT} 3 / 4, \mathrm{pN} 2 / 3$, positive or 
Table 2 Univariate Cox regression analysis of clinicopathological variables affecting survival outcomes of 93 patients with hypopharyngeal squamous cell carcinoma

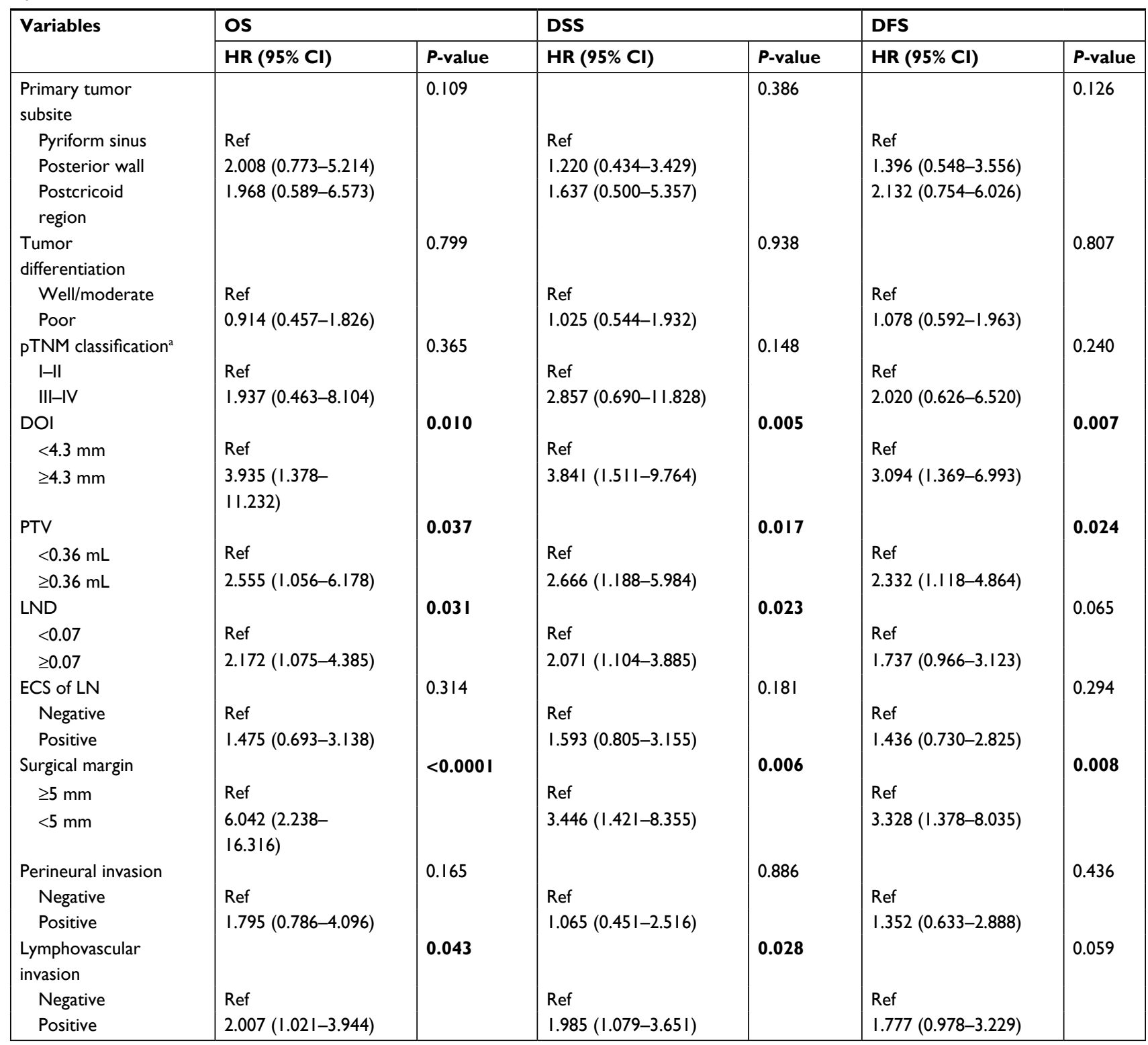

Notes: aTumor-node-metastasis staging system proposed by the American Joint Committee on Cancer (seventh edition). Bold values indicate $P$-value $<0.05$.

Abbreviations: DFS, disease-free survival; DOI, depth of invasion; DSS, disease-specific survival; ECS, extracapsular spread; LN, lymph node; LND, lymph node density; OS, overall survival; PTV, primary tumor volume; PTNM, pathological tumor-node-metastasis; Ref, reference.

close surgical margins, ECS of the LNs, perineural invasion, and lymphovascular invasion, according to the NCCN guidelines. ${ }^{13}$ Nevertheless, some patients continue to face a dismal prognosis. ${ }^{8,9,11,12,14}$ Over the past decade, more attention has been directed toward the risk factors of surgical specimens, in addition to tumor-node-metastasis (TNM) staging, that might influence clinical outcomes. ${ }^{8-12,14-18}$ Generally, the size and extent of the local spread of the primary tumor and the extent of regional dissemination are chief determinants of the prognosis in this distinct entity.
The DOI reflects the third dimension of the primary tumor. It is not only a quantitative assessment of the deepest anatomical structures reached by the tumor but also a qualitative indicator of the aggressive potential for local infiltration. It is well established that tumor cells with greater malignant potential are prone to invade vertically. ${ }^{15,22}$ The DOI can be considered a product of the biological aggressiveness of the primary tumor and the host's defense to the tumor. Increasing depth is considered to be correlated well with the occurrence of regional nodal disease in hypopharyngeal 
Table 3 Multivariate Cox regression analysis of potential variables affecting survival outcomes of 93 patients with hypopharyngeal squamous cell carcinoma

\begin{tabular}{|c|c|c|c|c|c|c|}
\hline & \multicolumn{2}{|l|}{ DOI } & \multicolumn{2}{|l|}{ PTV } & \multicolumn{2}{|l|}{ LND } \\
\hline & $\begin{array}{l}<4.3 \mathrm{~mm} \\
(\mathrm{n}=25)\end{array}$ & $\begin{array}{l}\geq 4.3 \mathrm{~mm} \\
(\mathrm{n}=68)\end{array}$ & $\begin{array}{l}<0.36 \mathrm{~mL} \\
(\mathrm{n}=25)\end{array}$ & $\begin{array}{l}\geq 0.36 \mathrm{~mL} \\
(\mathrm{n}=68)\end{array}$ & $\begin{array}{l}<0.07 \\
(n=43)\end{array}$ & $\begin{array}{l}\geq 0.07 \\
(n=50)\end{array}$ \\
\hline \multicolumn{7}{|l|}{ OS } \\
\hline 3 years & $85.4 \%$ & $68.7 \%$ & $79.0 \%$ & $70.6 \%$ & $82.2 \%$ & $65.2 \%$ \\
\hline 5 years & $75.9 \%$ & $44.7 \%$ & $63.2 \%$ & $47.8 \%$ & $58.3 \%$ & $46.5 \%$ \\
\hline $\mathrm{HR}(95 \% \mathrm{Cl})$ & $\begin{array}{l}4.513(1.034- \\
19.702)\end{array}$ & & $\begin{array}{l}3.625(1.242- \\
10.583)\end{array}$ & & $\begin{array}{l}2.854(1.242- \\
6.560)\end{array}$ & \\
\hline$P$-value & 0.045 & & 0.018 & & 0.014 & \\
\hline \multicolumn{7}{|l|}{ DSS } \\
\hline 3 years & $80.0 \%$ & $59.6 \%$ & $76.0 \%$ & $70.6 \%$ & $68.4 \%$ & $61.6 \%$ \\
\hline 5 years & $80.0 \%$ & $40.9 \%$ & $69.7 \%$ & $47.8 \%$ & $63.5 \%$ & $41.6 \%$ \\
\hline HR (95\% Cl) & $\begin{array}{l}3.466(1.022- \\
11.750)\end{array}$ & & $\begin{array}{l}2.757(1.129- \\
6.732)\end{array}$ & & $\begin{array}{l}2.033(1.015- \\
4.072)\end{array}$ & \\
\hline$P$-value & 0.046 & & 0.026 & & 0.045 & \\
\hline \multicolumn{7}{|l|}{ DFS } \\
\hline 3 years & $73.3 \%$ & $59.6 \%$ & $70.2 \%$ & $60.9 \%$ & $65.0 \%$ & $61.6 \%$ \\
\hline 5 years & $65.2 \%$ & $39.1 \%$ & $57.2 \%$ & $41.5 \%$ & $51.2 \%$ & $41.6 \%$ \\
\hline HR (95\% Cl) & $\begin{array}{l}3.004(1.019- \\
8.856)\end{array}$ & & $\begin{array}{l}2.408(1.057- \\
5.487)\end{array}$ & & & \\
\hline$P$-value & 0.046 & & 0.036 & & & \\
\hline
\end{tabular}

Note: Bold values indicate $P$-value $<0.05$.

Abbreviations: DFS, disease-free survival; DOI, depth of invasion; DSS, disease-specific survival; LND, lymph node density; OS, overall survival; PTV, primary tumor volume.
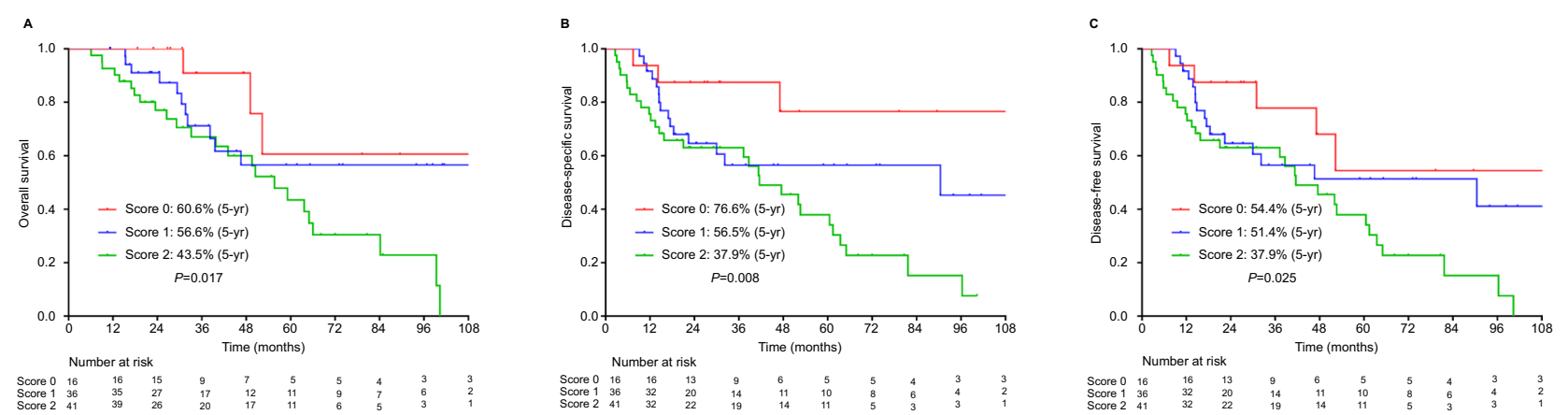

Figure 3 Kaplan-Meier survival curves of overall survival (A), disease-specific survival (B), and disease-free survival (C) according to the prognostic scoring system. Log-rank test, $P<0.05$.

Notes: *Scoring according to PTV (primary tumor volume) $\geq 0.36 \mathrm{~mL}$ and LND (lymph node density) $\geq 0.07$.

cancer. ${ }^{16,17}$ However, reports relating to predicting survival are scarce ${ }^{15}$ On the contrary, the PTV encompasses all three dimensions of the tumor adequately. ${ }^{19,20}$ Larger tumor bulk is related to an increased number of clonogenic tumor cells and increased radioresistance due to tumor hypoxia. ${ }^{23,24}$ Additionally, volumetric staging has been documented to be an accurate predictor of prognosis superior to $\mathrm{T}$ staging in hypopharyngeal cancer., ${ }^{9,10,18}$

$\mathrm{N}+$ disease is generally claimed to be the most potent prognostic indicator of early regional relapse, distant metastasis, and inferior survival in patients with hypopharyngeal cancer. ${ }^{2,5,6,8,11,12,14} \mathrm{~N}+$ hypopharyngeal cancer is staged as III/IV according to the AJCC staging system and is well established as a major matter of concern, with at least a $25 \%$ reduction in OS. ${ }^{5}$ The LND, incorporating the burden of regional nodal disease with the extent of nodal dissection, addresses the role of neck dissection as both a diagnostic and therapeutic procedure. Assessment accuracy is determined by three essential elements: the standard range of neck dissection, consummate surgical skills, and pathological measurement. The LND has been found to be a better indicator of prognosis in hypopharyngeal cancer than $\mathrm{N}$ staging. ${ }^{8,11,12,14}$

In summary, the DOI and PTV assess the primary tumor mass, while the LND is a better indicator of the regional nodal burden. The current study clearly shows that higher DOI, PTV, and LND are predictive of poorer prognosis in 
hypopharyngeal cancer patients. As the PTV incorporates the DOI in its calculation, we formulated a scoring system using the PTV and LND to define distinct prognostic groups for further analysis. The combination of these two novel prognostic scores had a significant impact on survival prognosis. Current strategies may not be sufficient for patients with one or more of the above risk factors.

Although our results are consistent with those of previous related studies, some notable limitations might impede the reliability of these prognostic indicators, such as different cancer entities, ${ }^{4,15-17}$ diverse therapeutic strategies, ${ }^{10,18}$ and relatively small populations. ${ }^{9-11,16,17}$ Additionally, the volumetric assessment methods adopted are time-consuming, or labor-intensive, or based on nonuniform criteria. ${ }^{10,18}$

The major strengths of our study are the uniform grouping criteria and treatment modalities, as well as the limitation of the analysis specifically to primary hypopharyngeal cancer patients treated surgically with/without adjuvant therapy. Moreover, we incorporated three potential variables and provided further confirmation of the prognostic value greatly expanded by their combination in these patients; to the best of our knowledge, this is the first report to demonstrate these important findings.

The principal limitations are mainly associated with the relatively few included cases and the retrospective nature of the study with potential bias in the patient selection and follow-up data. On the contrary, cross-validation or multiple testing was not established, which may lead to overoptimistic results. The cutoff value of variables determined by ROC analysis neglected the time effect when selecting the morality as the endpoint event. Large-scale prospective trials are needed to validate our results and confirm the clinical significance of these variables in this setting.

\section{Conclusion}

Although TNM staging reflects the overall disease status, it does not adequately assess tumor burden or biological activity. Our results suggest that prognostic stratification could be improved with evaluation of the DOI, PTV, and LND for the more appropriate selection of suitable candidates for more aggressive adjuvant therapy.

\section{Acknowledgment}

This research did not receive any specific grant from funding agencies in the public, commercial, or not-for-profit sectors.

\section{Disclosure}

The authors report no conflicts of interest in this work.

\section{References}

1. Carvalho AL, Nishimoto IN, Califano JA, Kowalski LP. Trends in incidence and prognosis for head and neck cancer in the United States: a site-specific analysis of the SEER database. Int J Cancer. 2005;114(5):806-816.

2. Hall SF, Groome PA, Irish J, O'Sullivan B. The natural history of patients with squamous cell carcinoma of the hypopharynx. Laryngoscope. 2008;118(8):1362-1371.

3. Cooper JS, Porter K, Mallin K, et al. National Cancer Database report on cancer of the head and neck: 10-year update. Head Neck. 2009;31(6):748-758.

4. Huang YC, Lee YC, Tseng PH, et al. Regular screening of esophageal cancer for 248 newly diagnosed hypopharyngeal squamous cell carcinoma by unsedated transnasal esophagogastroduodenoscopy. Oral Oncol. 2016;55:55-60.

5. Spector JG, Sessions DG, Haughey BH, et al. Delayed regional metastases, distant metastases, and second primary malignancies in squamous cell carcinomas of the larynx and hypopharynx. Laryngoscope. 2001;111(6):1079-1087.

6. Werner JA, Dünne AA, Myers JN. Functional anatomy of the lymphatic drainage system of the upper aerodigestive tract and its role in metastasis of squamous cell carcinoma. Head Neck. 2003;25(4):322-332.

7. Ho CM, Lam KH, Wei WI, Yuen PW, Lam LK. Squamous cell carcinoma of the hypopharynx--analysis of treatment results. Head Neck. 1993;15(5):405-412.

8. Ye LL, Oei RW, Kong FF, et al. The prognostic value of preoperative prognostic nutritional index in patients with hypopharyngeal squamous cell carcinoma: a retrospective study. J Transl Med. 2018;16(1): 12 .

9. Baghi M, Bisdas S, Engels K, et al. Prognostic relevance of volumetric analysis in tumour specimens of hypopharyngeal cancer. Clin Otolaryngol. 2007;32(5):372-377.

10. Roh JL, Kim JS, Kang BC, et al. Clinical significance of pretreatment metabolic tumor volume and total lesion glycolysis in hypopharyngeal squamous cell carcinomas. J Surg Oncol. 2014;110(7):869-875.

11. Hua YH, Hu QY, Piao YF, et al. Effect of number and ratio of positive lymph nodes in hypopharyngeal cancer. Head Neck. 2015;37(1):111-116.

12. Joo YH, Cho KJ, Kim SY, Kim MS. Prognostic significance of lymph node density in patients with hypopharyngeal squamous cell carcinoma. Ann Surg Oncol. 2015;22(Suppl 3):1014-1019.

13. National Comprehensive Cancer Network [webpage on the Internet]. NCCN guidelines. Available from: https:/www.nccn.org/professionals/ physician_gls/default.aspx\#head-and-neck. Accessed October 10, 2018.

14. Lo WC, Wu CT, Wang CP, et al. The pretreatment neutrophil-tolymphocyte ratio is a prognostic determinant of T3-4 hypopharyngeal squamous cell carcinoma. Ann Surg Oncol. 2017;24(7):1980-1988.

15. Moore C, Kuhns JG, Greenberg RA. Thickness as prognostic aid in upper aerodigestive tract cancer. Arch Surg. 1986;121(12):1410-1414.

16. Ambrosch P, Kron M, Fischer G, Brinck U. Micrometastases in carcinoma of the upper aerodigestive tract: detection, risk of metastasizing, and prognostic value of depth of invasion. Head Neck. 1995;17(6):473-479.

17. Tomifuji M, Imanishi Y, Araki K, et al. Tumor depth as a predictor of lymph node metastasis of supraglottic and hypopharyngeal cancers. Ann Surg Oncol. 2011;18(2):490-496.

18. Yang CJ, Kim DY, Lee JH, et al. Prognostic value of total tumor volume in advanced-stage laryngeal and hypopharyngeal carcinoma. J Surg Oncol. 2013;108(8):509-515.

19. Williams SS, Alosco TR, Mayhew E, Lasic DD, Martin FJ, Bankert RB. Arrest of human lung tumor xenograft growth in severe combined immunodeficient mice using doxorubicin encapsulated in sterically stabilized liposomes. Cancer Res. 1993;53(17):3964-3967.

20. Kuriakose MA, Loree TR, Hicks WL, Welch JJ, Wang H, Delacure MD. Tumour volume estimated by computed tomography as a predictive factor in carcinoma of the tongue. Br J Oral Maxillofac Surg. 2000;38(5):460-465. 
21. Takes RP, Strojan P, Silver CE, et al. Current trends in initial management of hypopharyngeal cancer: the declining use of open surgery. Head Neck. 2012;34(2):270-281.

22. Clark WH, From L, Bernardino EA, Mihm MC. The histogenesis and biologic behavior of primary human malignant melanomas of the skin. Cancer Res. 1969;29(3):705-727.
23. Johnson CR, Thames HD, Huang DT, Schmidt-Ullrich RK. The tumor volume and clonogen number relationship: tumor control predictions based upon tumor volume estimates derived from computed tomography. Int J Radiat Oncol Biol Phys. 1995;33(2):281-287.

24. Lartigau E, Le Ridant AM, Lambin P, et al. Oxygenation of head and neck tumors. Cancer. 1993;71(7):2319-2325. 


\section{Supplementary materials}

\begin{tabular}{c|c|c|c|}
\hline & DOI & PTV & LND \\
\hline DOI & & 0.876 & 0.660 \\
\hline PTV & 0.876 & & 0.513 \\
\hline LND & 0.660 & 0.513 & \\
\multicolumn{4}{c}{ Correlation $<0.8$} \\
\multicolumn{3}{r|}{ Correlation $\geq 0.8$}
\end{tabular}

Figure SI Correlation between pathological variables. Pearson correlation coefficient, $P<0.05$.

Abbreviations: DOI, depth of invasion; LND, lymph node density; PTV, primary tumor volume.

\section{Publish your work in this journal}

Cancer Management and Research is an international, peer-reviewed open access journal focusing on cancer research and the optimal use of preventative and integrated treatment interventions to achieve improved outcomes, enhanced survival and quality of life for the cancer patient. The manuscript management system is completely online and includes

a very quick and fair peer-review system, which is all easy to use. Visit http://www.dovepress.com/testimonials.php to read real quotes from published authors. 